Strahlenther Onkol 2004;180:340-50, DOI 10.1007/s00066-004-1219-0

\title{
Verification of IMRT: Techniques and Problems
}

Ludwig Bogner, Josef Scherer, Marius Treutwein, Matthias Hartmann, Franz Gum, Axel

Amediek

Klinik und Poliklinik für Strahlentherapie

Universität Regensburg

Purpose: IMRT (intensity modulated radiotherapy) verification techniques are reviewed together with investigations, demonstrating the intrinsic verification problems.

Material and Methods: Different IMRT verification procedures for either class solutions or individual patients are demonstrated. Among the latter are techniques like fluence or 3D-dose distribution verification within a transfer phantom. Different radiographic films and absolute dose probes are investigated for their suitability. Finally Monte Carlo techniques (XVMC/VEF) are used for error detection and IMRT verification.

Results: During introduction of clinical IMRT for head and neck (H\&N) tumors we concurrently applied fluence, relative and absolute dose measurement in parallel. While fluence and relative dose are in rather good agreement with calculations, absolute dose is always low compared to the TPS (TMS 6.1A, Nucletron B.V.) by 5-7\%. This deviation seems to depend not on the number of segments, but can strongly depend on MLC misalignment. Further investigations have revealed the importance of a detailed commissioning of the TPS down to the small-field range using diamond or diode probes and its detailed verification. In addition simple tests have shown that dose calculation approximations in the IMRT option of TMS are one major source of the dose deviation. XVMC/VEF does not use such approximations.

Conclusion: The procedure starts with a detailed TPS commissioning and verification process. Different verification methods are recommended during clinical IMRT implementation phase in order to locate sources of error. Later on, a minimal program could consist of a fluence or a relative dose verification procedure with few films and absolute dose measurement, followed by an intensive MLC quality assurance (QA). Inverse Monte Carlo systems like $\mathrm{IMCO}_{++} / \mathrm{IKO}$ or Hyperion, seem to be able to reduce the effort.

Key Words: IMRT, Verification, QA, Monte Carlo, TPS commissioning 


\section{Verifikation der IMRT: Techniken und Probleme}

Ziel: Neben einem Überblick über Verifikationstechniken der IMRT (intensitätsmodulierten Radiotherapie) werden Untersuchungen zu intrinsischen Verifikationsproblemen gezeigt. Material und Methodik: Verschiedene Verifikationsmethoden für Klassenlösungen sowie für individuelle Patientenpläne werden demonstriert, wie etwa Fluenz- und dreidimensionale Dosisverteilungen in einem Ersatzphantom. Dazu werden verschiedene Radiographiefilme und Absolutdosissonden auf ihre Eignung untersucht. Monte Carlo Techniken (XVMC/VEF) werden zur Fehleranalyse eingesetzt und auf ihre Tauglichkeit zur Verifikation untersucht. Ergebnisse: Bei der klinischen Einführung der IMRT bei Kopf-Hals- Tumoren wurden parallel Fluenz-, relativ- und absolutdosimetrische Verfahren zur Verifikation angewandt. Während die Fluenz- und Dosisverteilungen gut mit den Berechnungen übereinstimmen, sind die Absolutdosen systematisch um 5-7\% niedriger als die mit dem TPS (TMS 6.1A) berechneten. Die Abweichung scheint nicht von der Gesamtzahl der Segmente des Plans abzuhängen, kann aber relativ stark aber von einer relativ geringen Abweichung der MLCLeaves vom Sollwert abhängen. Weitere Untersuchungen zeigen auf, wie wichtig eine detaillierte TPS-Kommissionierung bis in den Bereich kleiner Feldgrößen mit umfangreichen Verifikationen und einfachen Tests ist. Damit konnte ein wichtiger Beitrag zum Dosisfehler, nämlich zusätzliche Näherungen bei der Dosisberechnung von IMRT-Plänen, verantwortlich gemacht werden. XVMC/VEF verwendet keine derartigen Näherungen.

Schlussfolgerung: Die Prozedur beginnt mit einer detaillierten TPS-Kommisionierung und Verifikation. Während der klinischen Einführungsphase sollten unterschiedliche Verifikationsverfahren eingesetzt werden, um etwaige Fehler aufzuspüren. Später kann ein Minimalprogramm verwendet werden, das entweder aus Fluenz- oder Relativdosismessungen in Verbindung mit einer Absolutdosisbestimmung besteht. Unabhängig davon sollte eine intensive Qualitätssicherung (QS) des MLCs erfolgen. Inverse Monte Carlo Systeme wie $\mathrm{IMCO}_{++} / \mathrm{IKO}$ oder Hyperion sind vermutlich geeignet, den Aufwand beträchtlich zu reduzieren.

Schlüsselwörter: IMRT, Verifikation, QS, Monte Carlo, TPS-Kommissionierung 


\section{Introduction}

While IMRT treatments of patients started some years ago in the USA, the introduction into clinical routine has proceeded much slower in Germany. In the meantime, some institutions have obtained experience in IMRT treatments, and a large community of radiation oncology departments are in the starting phases.

Many methods for small-field dosimetry in IMRT, such as those using different dosimeters like TLDs, semiconductor diodes, diamond detectors or ionisation chambers with small volumes have been tested (e.g. [19]). Verification methods for use in clinical practice were recently published by Ezell et al. [8], MacKenzie et al.[23], Rhein et al. [25] and others. There is a critical review within a report of the IMRT Collaborative Working Group of the National Cancer Institute of USA [5], which contains a summary of IMRT-verification methods and their problems.

The purpose of this paper is to give an overview over IMRT verification strategies and methods, demonstrated on head and neck $(H \& N)$ cancer cases. The investigations have revealed weak links in the entire chain of therapy planning system (TPS) commissioning treatment planning - delivery - verification and yield a critical assessment of what can be used to minimize errors in IMRT dose delivery. Finally, we derive a verification procedure, which seems reliable and practicable.

\section{Material and Methods}

\section{IMRT Method}

The treatment of H\&N cancers by means of IMRT was started in 2002, by using a seven beam technique equally spaced in the posterior hemisphere according to Hunt et al. [16] with gantry angles from $90^{\circ}$ to $270^{\circ}$ in $30^{\circ}$ steps. A conventional anterior supraclavicular field is then added caudal to the IMRT part by means of a half beam technique. This additional field is not included in the fluence optimisation but in the weight optimisation in order to prevent under- or overdosage in the junction area (see Figure 6). For optimisation an extended planning target volume (EPTV) is used, defined by the application of an isotropic margin of $0.5 \mathrm{~cm}$ around the PTV. On the other hand the mean dose in the PTV is normalized to $100 \%$. One or both parotid glands, the spinal cord, the brain stem and the unspecified tissue outside the EPTV plus organs at risk (OARs) are included in the optimisation as OARs. Spinal cord and brain stem are extended by an isotropic safety margin of $0.7 \mathrm{~cm}$. In the objective 
function, dose-volume constraints are applied to all OARs. Two separate treatment protocols are under investigation. One applies a sequential boost technique with the same seven-field IMRT technique used in the preceding large-volume IMRT treatment. The other one makes use of a simultaneous integrated boost technique (SIB), as described by Wu et al. [31]. A precise patient setup is achieved by means of a stereotactic localization technique (H\&N mask system, BrainLAB $\left.{ }^{\circledR}\right)$.

\section{IMRT Verification Strategies}

Since IMRT is a sophisticated task for treatment planning as well as for realization of the treatment, a reliable quality assurance (QA) of the dose distribution within the patient is of extraordinary importance. The authors of the above mentioned report [5] stress that IMRT dose distributions are characterized by complex three-dimensional (3-D) dose gradients and a time-dependent fluence delivery, placing severe limitations on the dosimeters and techniques. They claim that, even today, the ionization chamber is a benchmark probe for IMRT dosepoint measurements. Additionally, radiographic film dosimetry is the tool of choice for 2-D dosimetry, taking into account that even relative dosimetry is a difficult task.

The clinical implementation of IMRT in H\&N tumor treatment revealed a variety of problems. First of all, dose calculation by means of pencil beam model with IMRT-specific approximations and disregarding small-field problems [1] (Ahnesjö 2002, personal communication; Murmann 2003, personal communication) is possibly too inaccurate in order to achieve reliable results in an inhomogeneous medium in case of very small fields or field segments, which results from a high resolution fluence segmentation. Deficiency in lateral scatter calculation algorithms leads not only to a systematic error, but additionally to a convergence error [17]. The latter originates from the reaction of the optimization process to dose errors by compensating them in an erroneous modification of the fluence distributions.

Another issue regarding the accuracy of treatment planning systems is the inappropriate modelling of treatment head details, which, in fact, turns out to strongly influence the accuracy of output factors and beam profiles in case of small irregular fields, especially in off-axis positions. It seems that the requirements for commissioning of IMRT should be similar to the process used in stereotactic radiosurgery. Commissioning data set must be carefully examined, if the requirements for IMRT are met. The profiles should be measured with suited detectors, like microchamber, diode or diamonds. Output factors should be 
measured down to the smallest possible segment size. Simple multileaf modulated beams should be generated and the absolute dose verified in a slab phantom. These subbeams should be calculated as single fields as well, because different algorithms are often used for modulated as opposed to unmodulated beams.

These are some reasons why careful and multiple verification methods of IMRT treatment plans must be done to try to separate the different sources of inaccuracies and to correlate them to TPS, verification- or delivery-associated problems. From such a study, reliable verification techniques can presumably be derived, and remaining TPS-associated errors can be explained and regarded for corrections.

IMRT plan verification would require, in principle, an inhomogeneous anthropomorphic phantom identical to the patient. A realistic solution of the problem could be a separation of the problem into a two-step procedure, starting a new treatment technique for a distinct tumour entity and site with a class solution verification method. After having investigated the overall accuracy of the IMRT class solution, simpler methods have to be applied before each individual patient treatment in order to verify it.

\section{Verification of Class Solutions}

A classical method for verification of class solutions is the application of the treatment technique to a RANDO $®$ phantom and applying TLDs, in combination with radiographic film dosimetry, to it (e.g. [23]). With this method, a quasi-3-D dose verification can be established with reasonable accuracy. Special care must be taken of TLD response beam quality factors in different depths of a mixed multiple-beam setup. A very new and promising technique, especially suitable for true 3-D dose distributions with high dose gradients, is gel dosimetry. This method avoids the discontinuous measurement of TLD, where accidental hot or cold spots could remain undetected. Fricke or polymer gels are active integrating dosimeter substances, which can be brought to any shape within an anthropomorphic mold. Whereas Fricke gel can principally be applied in inhomogeneous anthropomorphic phantoms, including active lung gels $[12,26]$, they offer one severe disadvantage. Steep dose gradients change with time due to ionic diffusion effects. Polymer gels, on the other hand, reveal the opposite behaviour, because they are too sensitive to oxygen to be used as active measuring gels for lungs. On the other hand, diffusion is not an issue for this gel family [6]. In spite of this very promising research on so-called normoxic polymer gels will make ideal 3-D geldosimeters available in future. 
Another technique of dose verification is becoming interesting, as computer hardware gets more and more powerful: the Monte Carlo (MC) dose simulation [15, 20, 22]. MC techniques are said to be the most precise dose engines, because, in principle, their accuracy depends only on the number of photons sampled [9]. A remaining problem is, as in the case of convolution-based algorithms, the necessity of a very detailed treatment head model and its commisioning in order to correctly describe output factors and beam profiles of small irregular fields. Once having benchmarked a MC code, this method will be perhaps the most reliable technique for class solution dose verification in future.

\section{Verification of Individual Patient Plans}

Verification of treatment plans, individually for each patient, can basically be done by two different methods. The possibly easier way consists of the measurement of the fluence distribution separately for each modulated treatment field, but the task group report [5] stresses, that " as no mechanism currently exists for independently verifying that the delivered fluence yields the desired dose distribution, an independent determination of the measured and calculated dose distribution coordinates is essential”. In any case, even after succeeding to prove that it is sufficient to verify the fluence distributions of all fields, an absolute dose determination in at least at one suitable point within a smoothly modulated area of each field by ionization chamber (IC) dosimetry or another reliable probe is mandatory. Because of the remaining inaccuracies of the TPS, described above, comparisons of these point doses with the correlated calculated doses must be regarded within an accuracy evaluation concept.

Moreover, as pointed out by the Ttask Group report, the calculated dose distribution must be accessed by an appropriate measurement. The only way to do this consists of a transfer of the optimized treatment plan to an easy accessible water equivalent or inhomogeneous phantom (transfer phantom). The shape and size of this phantom should be somewhat correlated with the shape of the treated area of the patient. This can be, in case of H\&N tumors, a solid water cylinder with a diameter of approximately $20 \mathrm{~cm}$. Such a phantom is easily accessible to dosimetry by radiographic films and absolute dose measurements by suitable probes for dose comparisons with calculated date (Figure 1). A still open question is, however, how sensitive calculation errors arising from the incorrectly handled lateral scatter components by the TPS can be detected in a homogeneous phantom. 


\section{Dosimeters, Phantoms, and Evaluation Tools for IMRT Verification}

As a simple TPS IMRT commissioning test we used nine equally weighted non-overlapping $3 \times 3 \mathrm{~cm}^{2}$ subfields to build a $9 \times 9 \mathrm{~cm}^{2}$ field. The dose was then measured with $0.3 \mathrm{~cm}^{3} \mathrm{IC}$ (M23332, PTW), diamond (M6003, PTW) and dosimetry diode (M60008, PTW) in a slab phantom (RW3, PTW) at the isocenter in $10 \mathrm{~cm}$ depth. The test case was planned as modulated beam with $1 \mathrm{~Gy}$ in the isocenter. Additionally, the example was calculated as one plan with the 9 single unmodulated fields.

Radiographic film dosimetry seems to be an easy task, but actually it has to be done extremely careful. One of the reasons is that most film materials, which are not water equivalent, are very sensitive to low-energy photons, produced in the process of depth penetration of a photon. Film dosimetry is, in principle, suitable for both verification methods described above.

Measurements of fluence distributions by means of film dosimetry are usually done in a water-equivalent slab phantom in a distinct depth, with the beam direction perpendicular to the plane of the film. The measurement within a phantom beyond the depth dose maximum as opposed to in-air measurements seems to be mandatory. Reasons are that the contributions of contaminant electrons and low-energy photons are not guaranteed to be constant and minor for all cases. In addition, the optical density of the film after irradiation only correlates with the dose, which itself is only proportional to the photon fluence, when a local secondary electron equilibrium exists [18]. Yet, comparisons of in-air and in-phantom investigations of fluence distributions, measured by means of a radiographic film (EDR2, Kodak) reveal only a minor difference in the order of $<2 \%$. For this kind of investigation, with perpendicular beam entrance to film plane, the choice of film type is not really essential, as long as one corrects properly the dependence of the optical density to the dose. In Figure 2, the results of four different radiographic films (Kodak X-OMAT, Kodak EC-V, CEA TVS, and Kodak EDR2) are presented. With the exception of the X-OMAT film, all reveal a relatively high linear response, but using a non-linear fit procedure makes almost all of them suitable, depending on the desired dose range. The CEA TVS film is suitable only up to $0,5 \mathrm{~Gy}$. Additional investigations on the EDR2 film dose-response curves from different phantom depths, shown in Figure 3, reveal no real dependence, but can be attributed to differences in film processing. A similar shift can be observed in a long-term investigation of dose-response curves in a phantom in constant depth. This effect is corrected during dose determination. 
The situation changes completely when applying film dosimetry to 3-D dose investigations within a transfer phantom, because in coplanar IMRT techniques, all beam angles are parallel to the plane of the film. It is well known that in such a situation low-energy photons, increasingly produced with increased depth, result in a higher response of the film, such leading to dose errors of up to $20 \%$. In an earlier study we have investigated filter methods for parallel beam angles by use of a $0.6 \mathrm{~mm}$ thick lead-filter, positioned symmetrically $5 \mathrm{~mm}$ from the film within the water-equivalent slab phantom, such yielding fairly good agreement within $7 \%$ with ionisation chamber curves in the range $>1.5 \mathrm{~cm}$. On the other hand, much better agreement without any filter at all is shown by the EDR2 film, in the depth range of 1$18 \mathrm{~cm}$ with a dose deviation to ionization chamber measurement $<4 \%$ (Figure 4 ).

Additionally, EDR2 can be used as an absolute dosimeter within an accuracy of about $+-3 \%$. Similar to the procedure of Rhein et al. [25], we apply a five-step dose calibration $(0.5, \ldots 4.5$ Gy), applied with field sizes of $5 \times 3 \mathrm{~cm}^{2}$ in $5 \mathrm{~cm}$ depth of RW3 within one autosequence of the record and verify $(\mathrm{R} \& \mathrm{~V})$ system Primeview \& Lantis (Siemens) that exposes all fields to one film. It is important, during the corresponding ionization chamber measurement, to apply the complete sequence for the measurement of each individual subfield to account for scatter contributions from the remaining fields. As film and/or film processing changes with time, it is important to integrate the film calibration procedure into every film dosimetric investigation. The calibration procedure includes a non-linear fit of the optical density versus dose data. One remaining question is whether any field size dependence influences the determination of dose distributions by means of EDR2 film dosimetry. For this reason, we investigated the output factor variation with field size by means of EDR2-film dosimetry, measured in a depth of $5 \mathrm{~cm} \mathrm{RW3}$ and compared it to ionization chamber based output factors (OFs). The result is shown in Figure 5, revealing a slight difference in OF of up to $2 \%$ in the quadratic field size range of 2-20 cm, which makes EDR2 film dosimetry still suitable for IMRT-verification in agreement with several other investigators (e.g. [7, 32].

Determination of the absolute dose in a dose reference point by means of ionization chamber dosimetry was done using a $0,3 \mathrm{~cm}^{3}$ thimble chamber (M23332/Unidos, PTW). Absolute dosimetry in IMRT verification is under discussion because of the necessity of spatial positioning with high precision for comparisons with treatment plans. As IMRT plans normally show a larger dose inhomogeneity than 3-D CRT plans, dose gradients can be high across modulation sizes down to $1 \times 1 \mathrm{~cm}^{2}$. To avoid volume effects due to inhomogeneity of the dose distribution, many authors suggest to use chambers with small volumes. For our 
own investigations we defined a cylindrical volume of interest (VOI) in a highly homogeneous region of the dose cube with an appropriate size to account for chamber volume and setup errors. Thus, we rid ourselves of the necessity to position a very small volume probe with highest precision.

MR Gel dosimetry is another new field under investigation for IMRT verification purposes, as described above. This not only for class solution verifications, but also for individual dosimetry within a transfer phantom. The method is, in principle, capable of delivering a true 3-D dose distribution within any phantom shape, filled with a homogeneous polymer gel, such avoiding the danger of undetecting hot or cold spots (e.g., $[6,12])$.

Finally, the use of Monte Carlo simulation for verification purpose, as described above, can be just as valuable for individual patient verification as for class solutions. But, of course, a code must be found, which is quick and precise enough, to deliver treatment plans for verification purpose within a reasonable time frame. We use XVMC, including the MC treatment head model VEF, as described by Fippel et al. [9-11], which we commissioned with data from our linac (Primus, Siemens) for $6 \mathrm{MV}$ photons. The MC code is integrated in our inverse $\mathrm{MC}$ optimisation programs, called $\mathrm{IMCO}_{++} / \mathrm{IKO}$, described by Hartmann et al. $[13,14]$. For verification purposes, the optimization is switched off, and XVMC/VEF is used for forward calculations of all beam segments as determined by the pencil-beam based IMRT treatment plan (TMS,Theranostic) and transferred via DICOM-RT.

Finally, all verification work requires the comparison of calculations with measurements of fluence in a slab phantom or dose distributions in a suitable transfer phantom. To be highly flexible in redefining evaluation goals we have developed our own verification software (IMRT-verif) by means of Matlab ${ }^{\circledR}$ (MathWorks) similar to others [29]. It accepts data in the DICOM-RT standard, using fiducial points (Figure 1) for matching, tilting, and rescaling picture resolution and normalization of pixel contents, etc. The evaluation procedure delivers a comparison of the processed raw data, its absolute and relative dose difference, and, additionally, a modified plot of absolute gamma values [21], with arrows per pixel, indicating the direction and size of distance-to-agreement deviation. 


\section{Results}

When starting with IMRT treatment of patients in our clinics in 2002, we preferred to use different and independent verification methods to reveal any possible sources of error. So we have applied EDR2 film fluence verification for the modulated beams. Figure 7 shows the result of a comparison of the measured and calculated fluence-proportional profiles of one modulated beam of the treatment plan, shown in Figure 6. It is composed of ten segments of a seven-beam IMRT plan with altogether 70 segments, applied to a slab phantom in $5 \mathrm{~cm}$ depth.

As second method, the verification by means of a cylindrical transfer phantom (Figure 1), as described above, was applied routinely to every IMRT patient plan. At first an absolute dose determination in one point of the transfer phantom, using IC or diode-dosimetry, was done, yielding a measured dose about $5-7 \%$ too low in all cases investigated so far. This absolute dose value was used to correct the monitor units of all segments in the further relative dosimetry investigation. In Figure 8a, the result of the evaluation of one of five axial EDR2 verification-films is shown, calibrated to absolute dose. The evaluation of the differences in this slice to TMS calculation in terms of relative dose difference (Figure 8b) and gamma plot (Figure $8 \mathrm{c}$ ) with a distance of agreement of $3 \mathrm{~mm}$ and $3 \%$ of dose shows a relative good agreement, with the exception of edge effects and hot spots. The absolute dose correction factor has been applied to the monitor units (Mus) of the patient treatment plan, as well.

The evaluation of the verification of five patient treatment plans, three of which had been calculated with a sequential boost and two with a SIB-technique [27, 31], showed absolute dose deviations, which seemed to depend on the number of segments. In five IMRT plans with about 70 segments we found deviations of $-6 \%( \pm 1,0 \%)$, whereas two boost cases with 30 segments somehow resulted in lower deviations of $-5 \%( \pm 1 \%)$. The external segmentation software IMfast (Siemens, [28]) was used to investigate if any dependence of absolute dose deviation from the number of segments for the same treatment plan exists. Starting from a TMS calculation with the built-in segmentation algorithm switched off, the resulting fluence distribution was externally segmented by IMfast with different restrictions to the number of segments. These plans were then transferred to the transfer phantom, followed by a comparison of absolute dose measurement to calculation. A comparison of two plans with 95 (on average 13.5 per gantry angle) and 29 (4.1 per beam) segments yielded a measured underdosage of $7.1 \%$ and $5.7 \%$. A simple IMRT example of nine non-overlapping segments 
of $3 \times 3 \mathrm{~cm}^{2}$ composing a $9 \times 9 \mathrm{~cm}^{2}$ field also showed a lower dose, when calculated as IMRT beam. The closer intercomparison of TMS 6.1A calculation as modulated rather than as "normal beams" revealed a $2.6-3.4 \%$ (for two "different" Siemens Primus linacs) dose error due to approximations made for IMRT beams. As a result, all these comparisons did not confirm a dependence of the dose difference on the total number of segments.

Large deviations can be found when investigating relative dose profiles normalized to $10 \times 10$ $\mathrm{cm}^{2}$ for very small IMRT segments by means of different calculations (TMS PB [pencil beam], CC [collapsed cone] and different dose probes (diode, pin-point IC, IC15, EDR2). In Figure 9, a small segment which fulfils the minimal requirements of TMS IMRT (aperture with $>9 \mathrm{~cm}^{2}$ and more than two leaf pairs open) is investigated, yielding dose deviations up to $9 \%$ for the pin-point IC and 5\% for EDR2, respectively, when compared to the diode as a reference probe. The calculation deviates up to $2.5 \%$ for $\mathrm{PB}$ and $5 \%$ for $\mathrm{CC}$, respectively.

Small field dosimetry on quadratic fields showed that TMS compares well with diamond measurements down to $2 \times 2 \mathrm{~cm}^{2}$ (Figure 10). At $1 \times 1 \mathrm{~cm}^{2}$ the TMS $6.1 \mathrm{~A}$ result gives a $23 \%$ lower output when compared to the diamond probe. Diode shows a $11 \%$ higher dose response, the $0,3 \mathrm{~cm}^{3}$ ionisation chamber is completely off due to the detector size. Another measurement revealed that a microionisation chamber with steel electrode (pin point) showed about $15 \%$ less dose than diamond at $1.2 \times 1.2 \mathrm{~cm}^{2}$.

Nucletron B.V. has improved the head model in TMS 6.1B, using our small-field data measured with a diamond detector. A TMS6.1B test with smaller and slightly elliptic source sizes (diameter of 0.265 and $0.235 \mathrm{~cm}$, respectively, compared to $0.48 \mathrm{~cm}$ in TMS 6.1A) showed that, even at $1 \times 1 \mathrm{~cm}^{2}$, the output can be accurately modelled.

Application of the new model to a patient case for comparison with the old model, strongly supports that small-field problems play a minor role, but instead, it is additional dose calculation approximations, which are only applied in IMRT (Murmann 2003, personal communication), which seem to play the major role.

In investigating the origin of the absolute dose deviation, additional research was done to determine how MLC misalignment influences absolute dose. Since MLC tolerance tables allow a $\pm 2 \mathrm{~mm}$ deviation of the nominal leaf position, we looked for the differences in absolute dose of the 70-segment patient plan when adding or subtracting $2 \mathrm{~mm}$ to every leaf 
within every segment as a worst case by means of a MC calculation. In doing so, we could detect a rather high influence of leaf position errors on the mean dose of about $8 \%$ (low by smaller and high by larger aperture) between both extremes (Figure 12).

When regarding the time-consuming verification methods, the question arises if $\mathrm{MC}$ dose verification could be a serious alternative. In Figure 11, a comparison of PB-based TMS IMRT and XVMC/VEF forward calculation of the TMS plan demonstrated (treatment plan of Figure 6) is shown in terms of dose-volume histograms (DVHs). The evaluation demonstrates that MC-calculation reveals dose differences, which must be attributed to the systematic and convergence errors [17] based on the PB approximations.

\section{Discussion}

A strategy for IMRT verification is presented and some of the methods proposed were applied to a real H\&N IMRT treatment plan. The simultaneous application of relative fluence and dose verification in a transfer phantom in combination with absolute dose verification by IC or diode dosimetry is time-consuming, but it demonstrated its sensitivity for the detection of errors which can occur in the IMRT chain. Whereas the fluence distributions of the modulated beams and the relative dose are in general good agreement with the calculated ones, we revealed systematic deviations in the absolute dose at a reference point. Our search for the causes of these deviations can be divided into four parts:

(1) Investigations of the probes used for the verification process showed clearly that for relative film dosimetry in a transfer phantom the EDR2 film is the only suitable one, whereas for relative fluence verification other films like XOMAT, EC-V are good as well. Investigations on probes for small-field absolute dose measurements showed that diodes and diamond detectors are suitable. IC-measured doses must be compared with averages of a suitably sized VOI around the dose reference point, chosen within a homogeneous area of the target. EDR2 film should not be used for absolute dosimetry, because its precision is restricted to $\pm 3 \%$, which is not high enough.

(2) The penumbra structures of the narrow beamlets in the transfer phantom are broader in the TMS calculations when compared to EDR2, as can clearly be 
seen in Figure 8a. The reasons for this difference could be the poorer spatial resolution of the dose cube and/or an erroneously determined focal spot size of TMS. The commissioning data set consists of profiles using a $0.13 \mathrm{~cm}^{3} \mathrm{IC}$ and output factors down to minimal field sizes of $5 \times 5 \mathrm{~cm}^{2}$ according to TMS recommendations in version TMS 6.1A. OFs for smaller fields are extrapolated due to missing data. The focal spot size evaluation is based on the measurements of the $10 \times 10 \mathrm{~cm}^{2}$ field, which is usually done with a medium volume chamber, although a high resolution detector would be required for this purpose. A new head model with elliptic source size (TMS 6.1B) commissioned by diamond-based OFs down to $1 \times 1 \mathrm{~cm}^{2}$ yield a rather good agreement.High deviations could also be found in the investigation of extremely small irregular field sizes (but within TMS default IMRT settings) with respect to beam profiles and OFs, showing again the necessity to measure data down to smaller field sizes with suitable probes like diamond or diodes for TPS commissioning.

(3) Our investigations strongly support that small-field problems play a minor role, but instead there are additional dose calculation approximations, which are only applied in IMRT (Murmann 2003, personal communication) which seem to play the major role. The dose deviations between measurement and calculation in a reference point in the transfer phantom and a simple IMRT test case demonstrated the TMS difference for IMRT calculation. "Normal beams" are calculated in TMS with fluence step functioned at field edge plus source blurring merged into the pencil beam kernel shape. Segmented multilieaf step-and-shoot modulation fields are handled differently than "normal beams". The total fluence is calculated by summing all segments, step-functioned at each segments edge, not just at the total field edge. Accompanied by implementation errors in 6.0 and 6.1A, overblurring occurred, possibly leading to a difference in transmission modelling. Thus, increasing the number of segments could lead to the observed increase in dose difference. In OTP (Nucletron B.V.) the dose deviation vanishes, because all segments are calculated without further approximations. All suggested improvements in head modelling and TPS commissioning also hold true for $\mathrm{XVMC/VEF}$. 
(4) Finally our investigations on MLC misalignment within the allowed tolerance reveal a major impact in IMRT dose delivery. The errors can, in principle, be detected by the fluence verification, described above. In any case it is recommended to spend more time in MLC QA instead of in individual patient QA [4]. In addition to the calibration of the leaves at gantry zero position, it should be checked whether the MLC alignment depends on the gantry angle or on the moving direction of the leaf. A misalignment of the MLC not only affects the absolute dose, but could also affect the position of the dose distribution. Both could result in overdosage of the OAR and too low dose in the PTV. The same holds true for a detailed QA of the isocenter position.

Realizing that special IMRT dose calculation approximations, treatment head modelling, and small-field dosimetry can offer a severe problem to IMRT TPS, including MC-based systems, special care must be taken in commissioning and verification, especially for small off-axis fields. It has to be emphasized that the manufacturer of a TPS must disclose all approximations of the IMRT algorithm, together with recommendations for base data measurement being sensitive to those. Moreover he must provide for a very detailed prerelease commissioning of the TPS, together with his beta test sites, and supply the customer with the results of this. It must be sufficient for a hospital physicist to restrict himself to a post-release TPS commissioning, which only can be a subset.

In spite of the discussed problems, IMRT is a method to spare the organs at risk and to get a sufficient dose in the PTV in one session $[24,30]$. The classic irradiation technique for H\&N tumors, on the other hand, claims multiple fields with over- or underdosage at field matchlines of electron and photon fields and does not allow sparing the parotids. Another source of error, relativizing the problems discussed in this paper, originates from the uncertainty of positioning, even when using a stereotactic mask system. 


\section{Conclusion}

The process of finding the most reliable verification process is perhaps close to its end. First the TPS, with its approximations and small-field behaviour, should be extensively verified after a very detailed commissioning phase. Second, an intensive MLC QA should be routinely run. Then, as a minimal individual verification concept, one should be able to reduce the procedure to either fluence or dose verification, but in both cases an absolute dose determination should be included for safety reasons. Both methods are sensitive to detect delivery problems.

An MC system like XVMC/VEF is extremely useful as a tool to detect different sources of errors during the IMRT introduction phase of a distinct tumor site. Especially in the H\&N or mediastinum region, pronounced systematic and convergence errors [17] can occur using the PB model. On the other hand, an MC system cannot be a verification tool for a PB-based TPS, as dose differences are a priori expected. So the only way to avoid the well-known problems of $\mathrm{PB}$ algorithm is to use inverse $\mathrm{MC}$ systems like $\mathrm{IMCO}_{++} / \mathrm{IKO}$ [3] or Hyperion [2] for IMRT. These systems avoid systematic and convergence errors completely, and an absolute dose verification should be done only for safety. Delivery can be controlled by an extended MLC QA and the interlock system.

\section{Acknowledgements}

This work was supported by the Deutsche Forschungsgemeinschaft. We want to thank A. Murman and A. Ahnesjö from Nucletron B.V. for supporting us with the head model calculations and other fruitful discussions.

\section{Address for Correspondence}

Priv.-Doz. Dr. Ludwig Bogner, PhD

Departement of Radiotherapy

University of Regensburg

Franz-Josef-Strauß-Allee 11

93042 Regensburg

\section{Germany}




\section{Literature:}

1. Ahnesjö A, Aspradakis MM. Dose calculations for external beams in radiotherapy. Phys Med Biol 1999; 44: R99-R155

2. Alber M, Birkner M, Laub W, Nüsslin F. Hyperion - An integrated IMRT planning tool. In: Schlegel W, Bortfeld T, Hrsg. The Use of Computers in Radiation Therapy, Berlin-Heidelberg-New York: Springer, 2000:46-8

3. Bogner L, Hartmann M . Inverse kernel methods in inverse treatment planning. 2004: manuscript in preparation

4. Bohsung J, Groll J et al. IMRT mit dynamischem MLC - Erfahrungen nach mehr als einem Jahr klinischer Routine. In: Welker K, Zink K., Hrsg., Medizinische Physik 2001, Berlin: DGMP, 2001: 165-6

5. Boyer AL, Butler EB, DiPetrillo TA et al. Intensity-modulated radiotherapy : current status and issues of interest. Int J Radiat Oncol Biol Phys 2001; 51,4: 880-914

6. De Deene Y : Gel dosimetry for the dose verification of intensity modulated radiotherapy treatments. Z Med Phys 2002; 12: 77-89

7. Esthappan J, Sasa M, Harms WB et al. Dosimetry of therapeutic photon beams using an extended dose range film. Med Phys 2002; 29(10): 2438-45

8. Ezzell GA, et al. Guidance document on delivery, treatment planning, and clinical implementation of IMRT: report on the IMRT Subcommitee of the AAPM Radiation Therapy Committee. Med Phys 2003;30:2089-115

9. Fippel M. Fast Monte Carlo dose calculation for photon beams based on the VMC electron algorithm. Med Phys 1999;26:1466-75

10. Fippel M, Haryanto F, Dohm O, et al. A virtual photon energy fluence model for Monte Carlo dose calculation. Med Phys 2003;30:301-11

11. Fippel M, Laub W, Huber B, et al. Experimental investigation of a fast Monte Carlo photon beam dose calculation algorithm. Phys Med Biol 1999;44:3039-54

12. Gum F, Scherer J, Bogner L, et al. Preliminary study on the use of an inhomogeneous anthropomorphic Fricke gel phantom and 3D magnetic resonance dosimetry for verification of IMRT treatment plans. Phys Med Biol 2002;47:67-77

13. Hartmann M., Bogner L. IKO - a new Monte Carlo based treatment planning system. 2004: manuscript in preparation

14. Hartmann M, Bogner L, Fippel M. IMRT: Inaccuracies of a conventional inverse pencil beam TPS, obtained by a comparison with a Monte-Carlo based TPS.

Radiother Oncol 2002; 64:Suppl.1:S96 
15. Hartmann M, Bogner L, Fippel M et al. IMCO++ - Ein Monte-Carlo-basiertes System für die IMRT. Z Med Phys 2002;12:97-108

16. Hunt MA, Zelefsky MJ, Wolden S et al. Treatment planning and delivery of intensitymodulated radiation therapy for primary nasopharynx cancer. Int J Radiat Oncol Biol Phys 2001;49,3:623-32

17. Jeraj R, Keall PJ, Siebers JV. The effect of dose calculation accuracy on inverse treatment planning, Phys Med Biol 2002;47:391-407

18. Johns HE, Cunningham JR. Measurement of radiation: Dosimetry. In: The Physics of Radiology, Fourth Edition. Springfield: Thomas, 1983:217-69

19. Laub W, Wong T. The volume effect of detectors in the dosimetry of small fields used in IMRT. Med Phys 2003;30:341-7

20. Leal A, Sanchez-Doblado F, Arrans R et al. Routine IMRT verification by means of an automated Monte Carlo simulation system. Int J Radiat Oncol Biol Phys 2003;56:58-68

21. Low DA, Harms WB, Mutic S, Purdy JA. A technique for the quantitative evaluation of dose distributions. Med Phys 1998; 25: 656-61

22. Ma CM, Pawlicki T, Jiang SB et al. Monte Carlo verification of IMRT dose distributions from a commercial treatment planning optimisation system. Phys Med Biol 2000; 45: 2483-95

23. MacKenzie MA, Lachaine M, Murray B et al. Dosimetric verification of inverse planned step and shot multileaf collimator fields from a commercial treatment planning system. J Appl Clin Med Phys 2002;3:97-109

24. Münter MW, Debus J, Hof $\mathrm{H}$ et al. Inverse treatment planning and stereotactic intensity-modulated radiation therapy (IMRT) of the tumor and lymph node levels for nasopharyngeal carcinomas. Strahlenther Onkol 2002;178:517-23

25. Rhein B, Häring P, Debus J, Schlegel W. Dosimetrische Verifikation von IMRTGesamtplänen am Deutschen Krebsforschungszentrum. Z Med Phys 2002;12:122-32

26. Scherer J, Solleder M, Schiess1 I et al. 3D MR-Gel-Dosimetrie mit lungenäquivalentem Gel. Z Med Phys 1998;4:201-208

27. Schulz-Ertner D, Didinger B, Nikoghosyan A, et al. Optimization of radiation therapy for locally advanced adenoid cystic carcinomas with infiltration of the skull base using photon intensity-modulated radiation therapy (IMRT) and carbon ion boost. Strahlenther Onkol 2003;179:345-51

28. Siochi RA. Minimizing static intensity modulation delivery time using an intensity solid paradigm. Int J Radiat Oncol Biol Phys 1999;43:671-80

29. Wiezorek T, Schwedas M, Scheithauer M et al. VERIDOS: A new tool for quality assurance for intensity modulated radiotherapy. Strahlenther Onkol 2002;178:732-36 
30. Wu Q, Manning M, Schmidt-Ullrich R et al. The potential for sparing of parotids and escalation of biologically effective does with intensity-modulated radiation treatments of the head and neck cancers; a treatment design study. Int J Radiat Oncol Biol Phys 2000;46:193-205

31. Wu Q, Mohan R, Morris M et al. Simultaneous integrated boost intensity-modulated radiotherapy for locally advanced head-and-neck squamous cell carcinomas. I: dosimetric results. Int J Radiat Oncol Biol Phys 2003;56:573-85

32. Zhu XR, Jursinic PA, Grimm DF et al. Evaluation for Kodak EDR2 film for dose verification of intensity modulated radiation therapy delivered by a static multileaf collimator. Med Phys 2002; 29(8): 1687-92 


\section{Figures:}

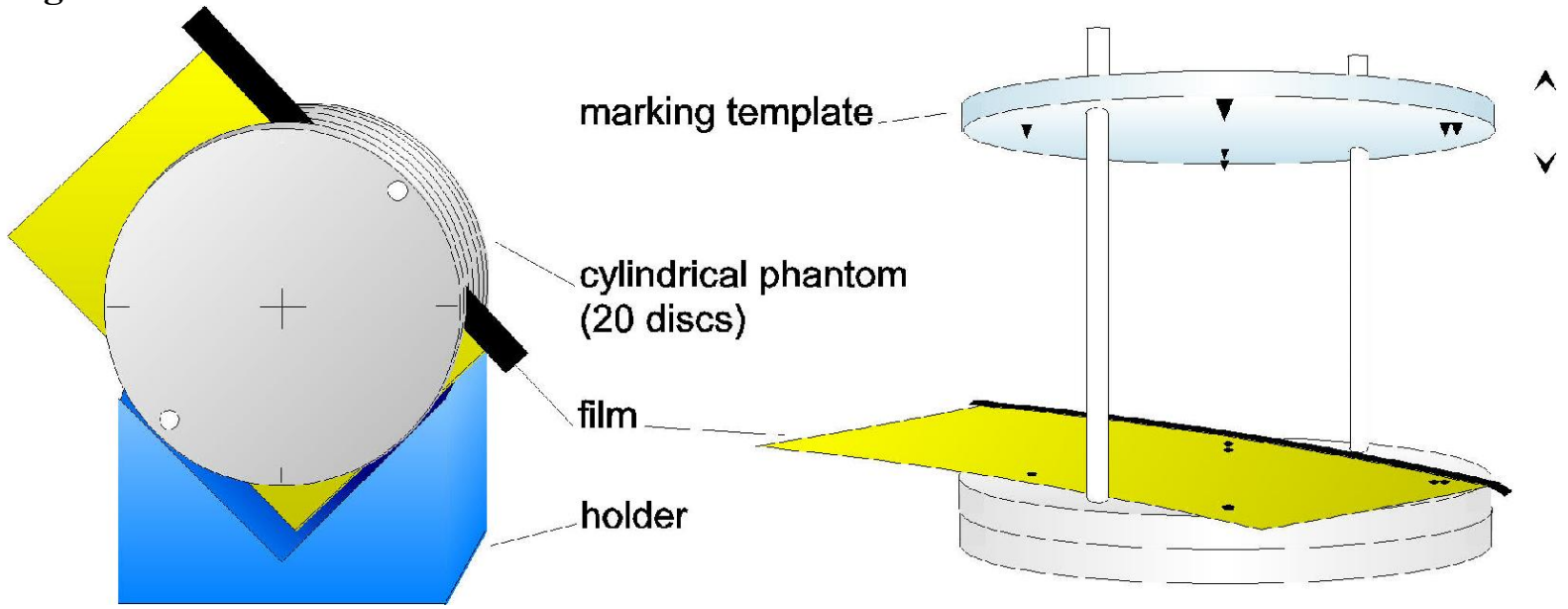

Figure 1 Scheme of a cylinder phantom as transfer phantom suitable for H\&N-IMRT verification, demonstrating the production of fiducial markers on the film.

Abbildung 1 Schema eines Transfer-Zylinderphantoms für Kopf-Hals-Tumoren mit Darstellung der Anbringung von Orientierungsmarkierungen auf dem Film.

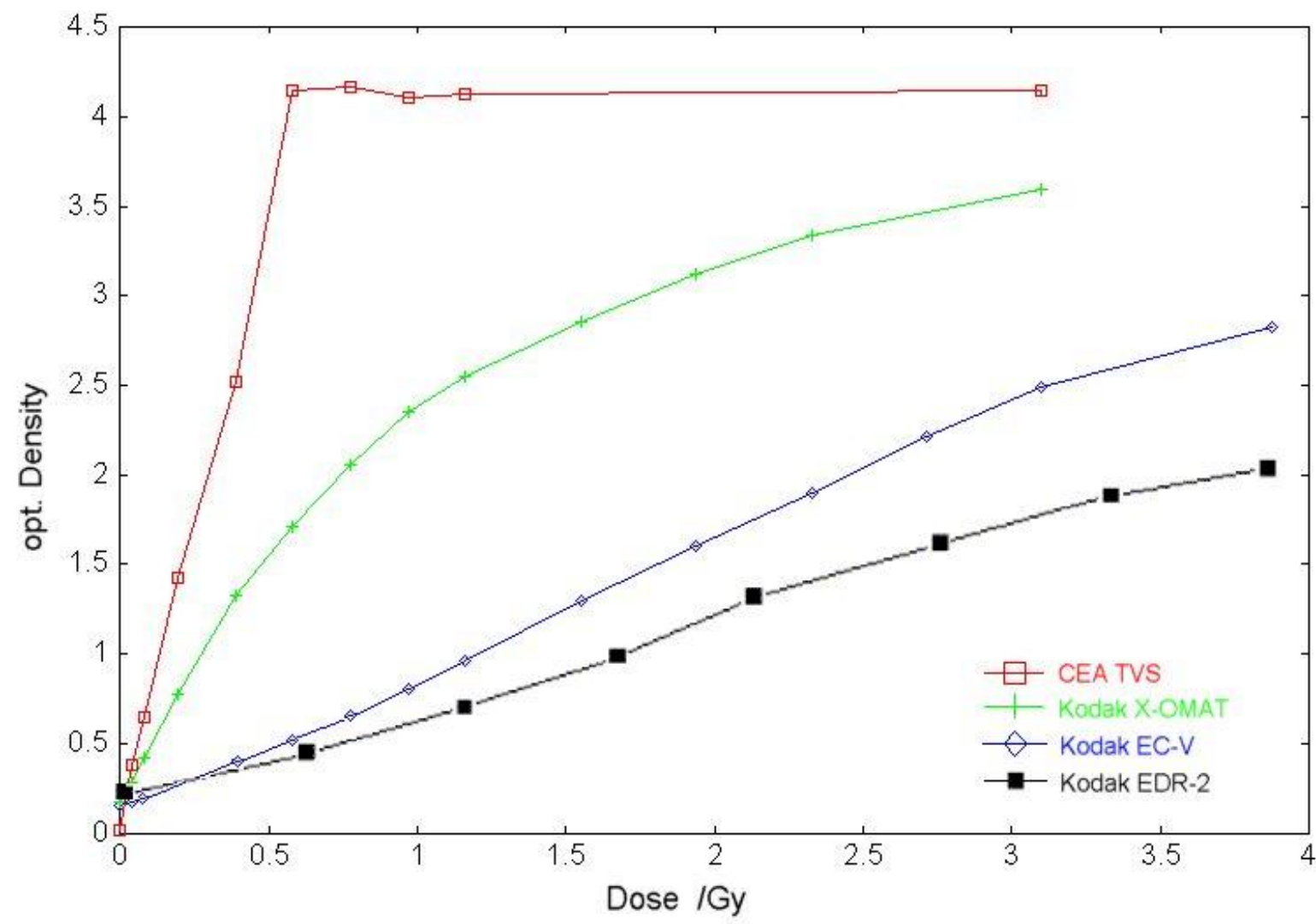

Figure 2 Comparison of the dose-response of different radiographic films.

Abbildung 2 Vergleich der optischen Dichte verschiedener Filmtypen als Funktion der Dosis. 


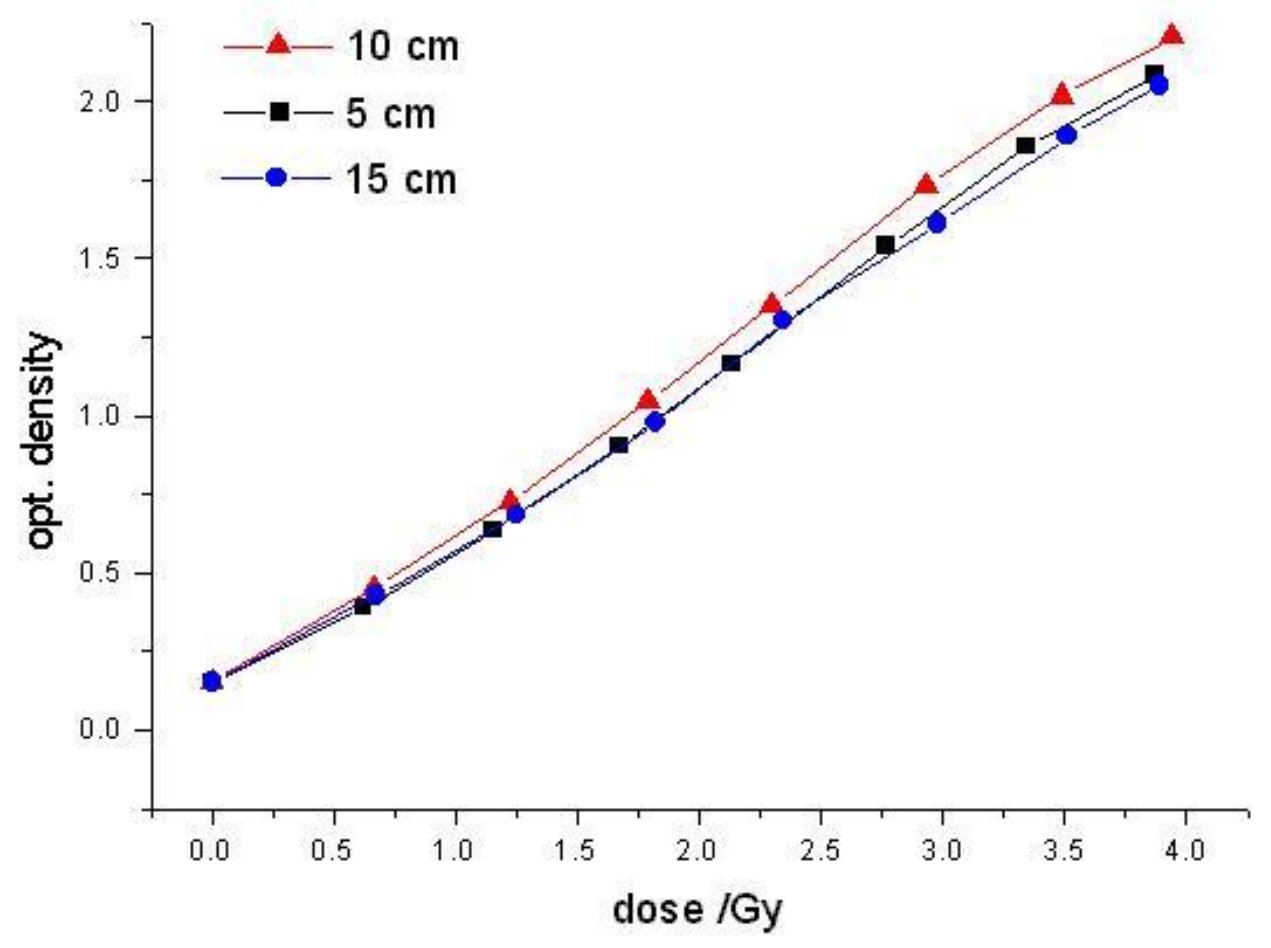

Figure 3 Dependence of the EDR2 (Kodak) dose-response curve from phantom depth Abbildung 3 Die optische Dichte als Funktion der Dosis für den EDR2 - Film in verschiedenen Tiefen. 


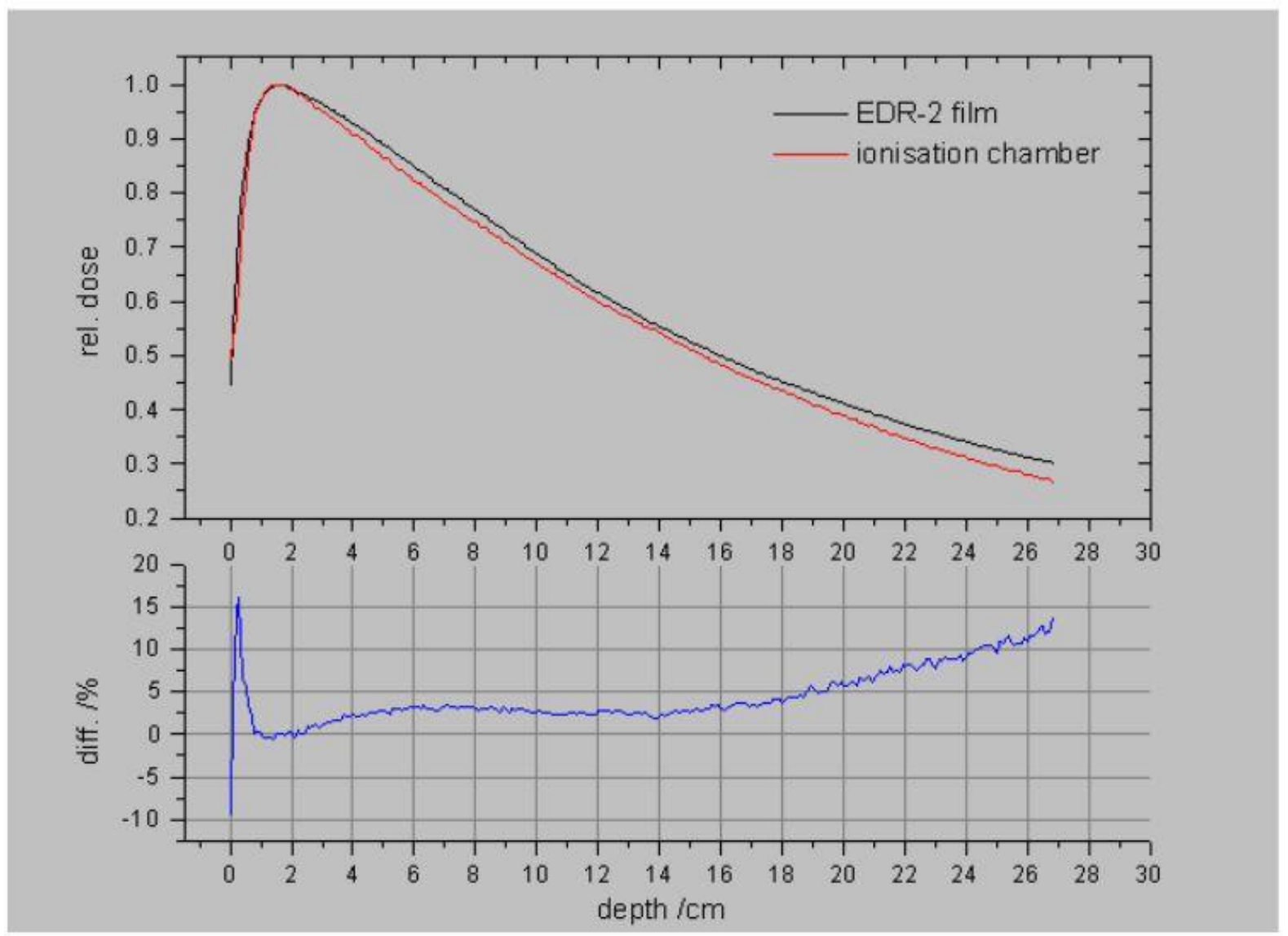

Figure 4 Comparison of depth dose curves, measured with EDR2 film dosimetry versus ionization chamber (top). Dose differences between ionisation chamber versus EDR2 (bottom).

Abbildung 4 Tiefendosiskurven mit EDR2-Filmdosimetrie versus Ionisationskammer (oben). Dosisdifferenzen zwischen der Ionisationskammer und EDR2 (unten). 

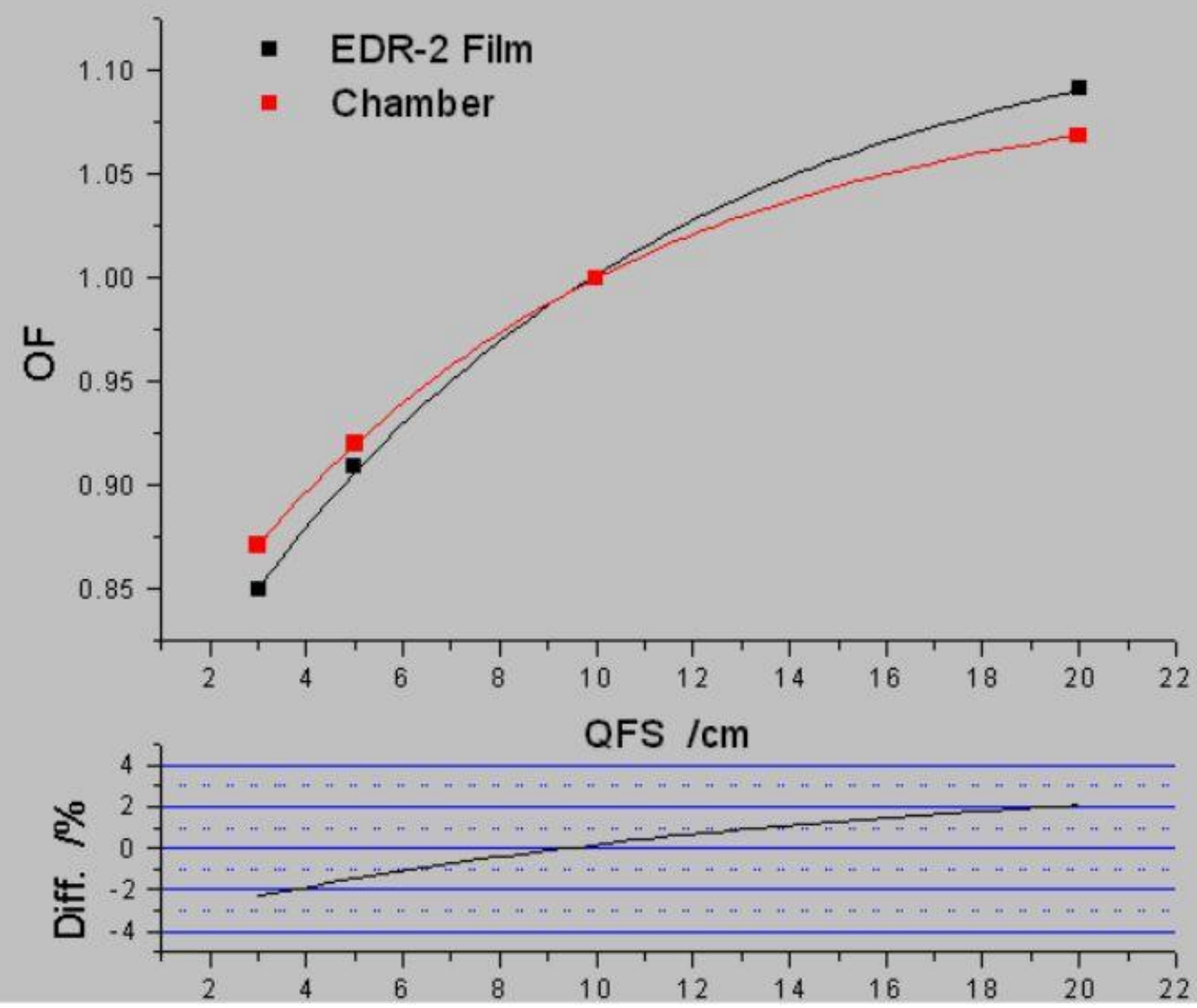

Figure 5 Comparison of EDR2 film dosimetry and IC based outputfactors of quadratic field sizes, measured in a depth of $5 \mathrm{~cm}$ (top) and OF-difference (bottom).

Abbildung 5 Outputfaktoren als Funktion der Quadratfeldgröße in $5 \mathrm{~cm}$ Tiefe, bestimmt mit EDR2 Film und Ionisationskammer (oben) und deren Differenz (unten). 


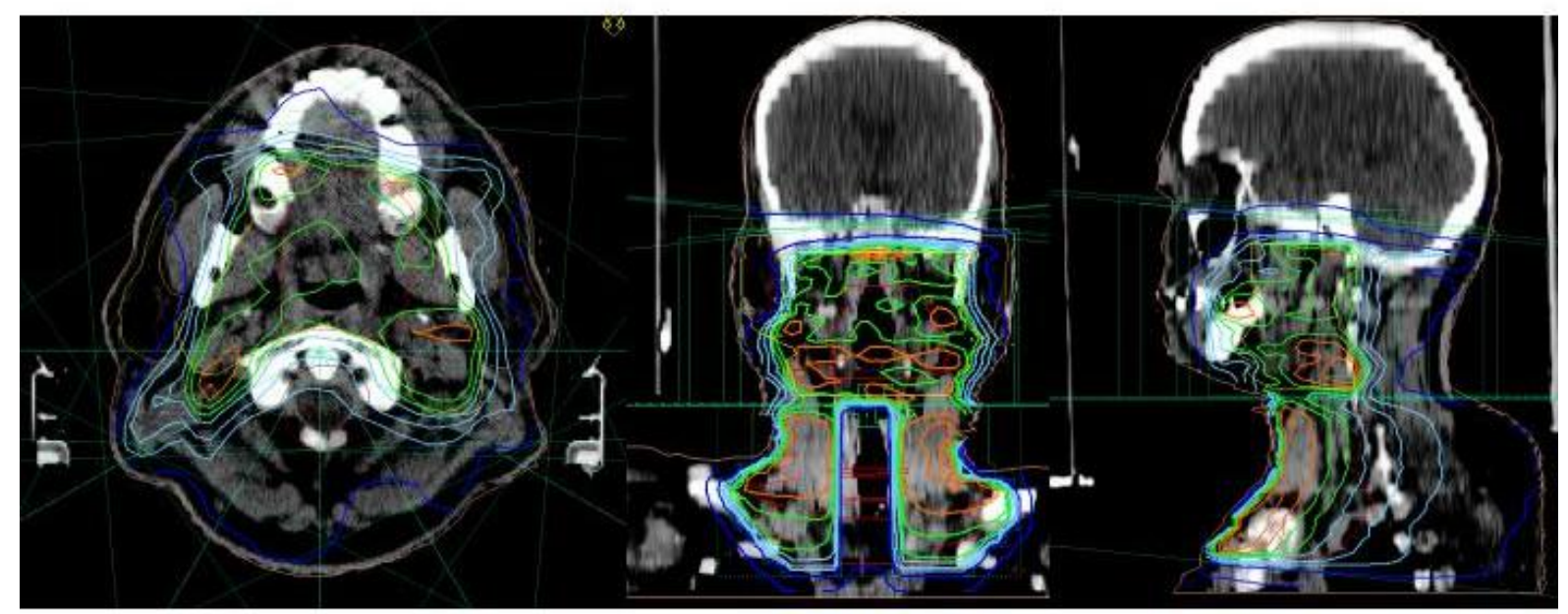

Figure 6 H\&N-IMRT plan calculated by TMS version 6.1A. The plan consists of seven modulated beams in half-beam technique. A conventional anteroposterior supra-half-beam is integrated by beam weight optimisation alone. Three-plane dose distribution is shown.

Abbildung 6 H\&N- IMRT-Plan berechnet mit TMS Version 6.1A. Der Plan besteht aus sieben modulierten Feldern in Halbfeldtechnik; ein konventionelles anteroposteriores-Supraclavicularfeld wird nur gewichtsoptimiert kaudal als Halbfeld angeschlossen. Darstellung einer Dosisverteilung in drei Ebenen.

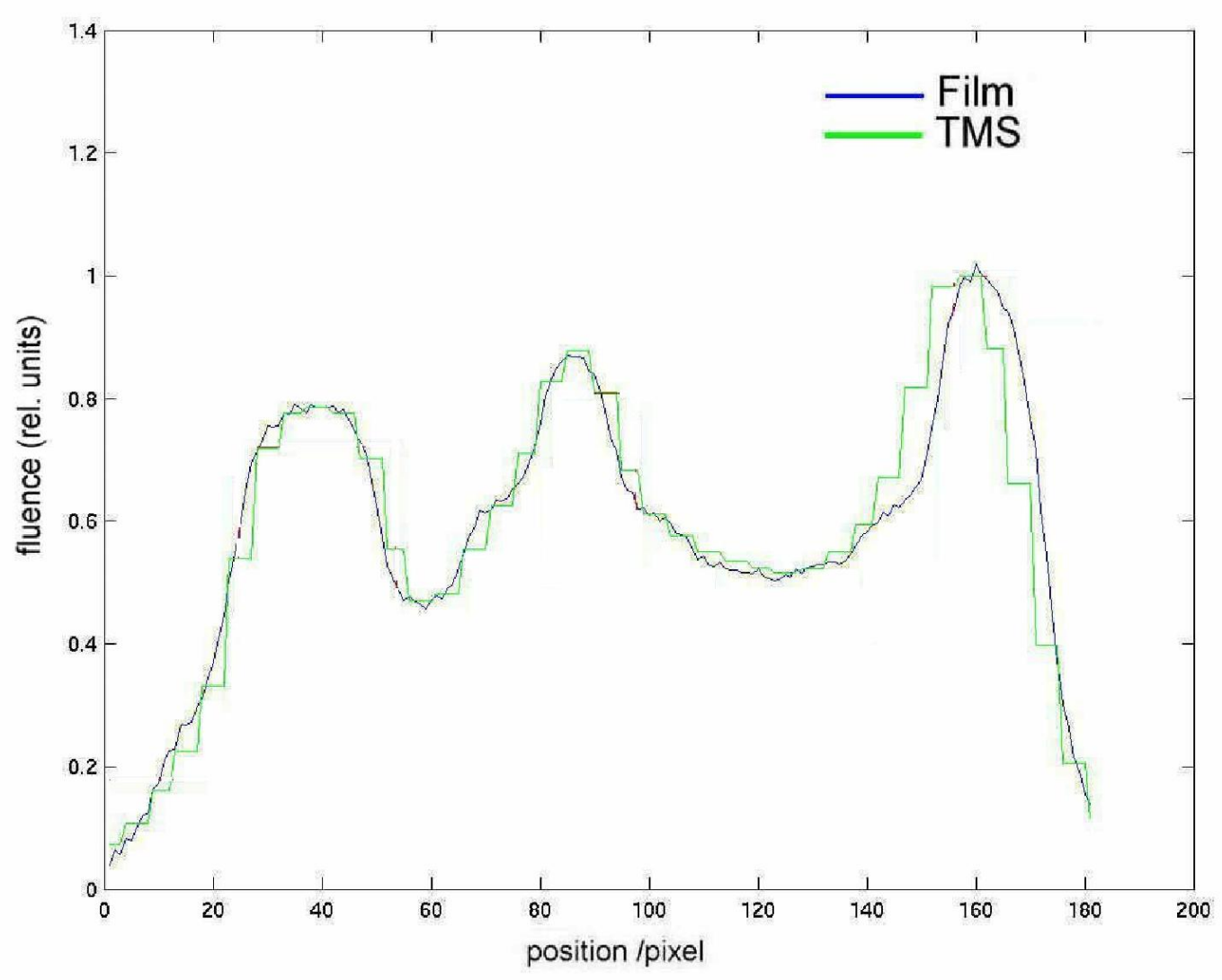


Figure $7 \quad$ Fluence verification by means of EDR2 film dosimetry and its evaluation. Measured and calculated fluence-proportional profiles, normalized to their maxima.

Abbildung 7 Fluenzverifikation mittels EDR2 - Filmdosimetrie: Gemessene und berechnete fluenz-proportionale Profile, normiert auf ihre Maxima.

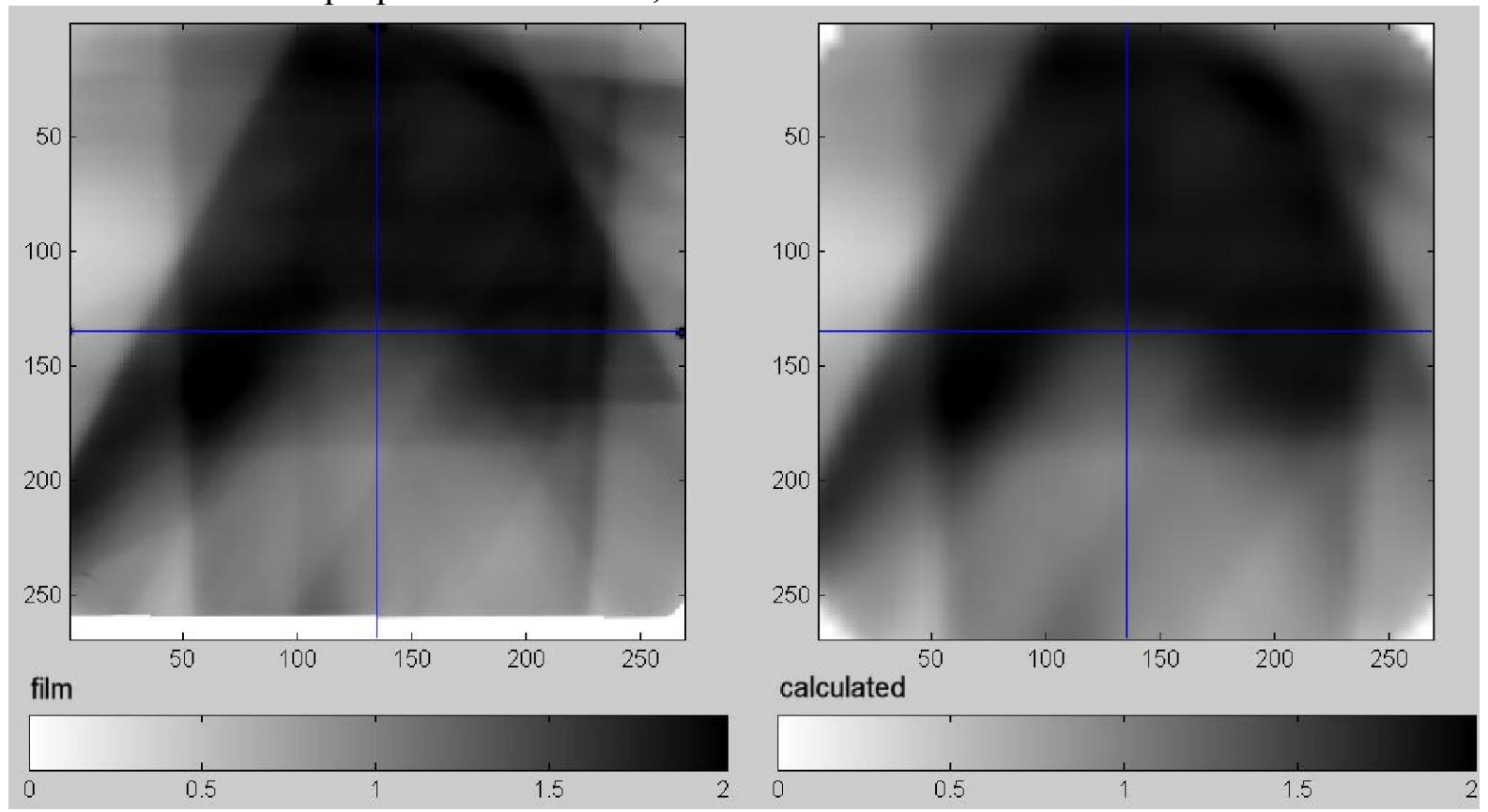

$8 \mathrm{a}$
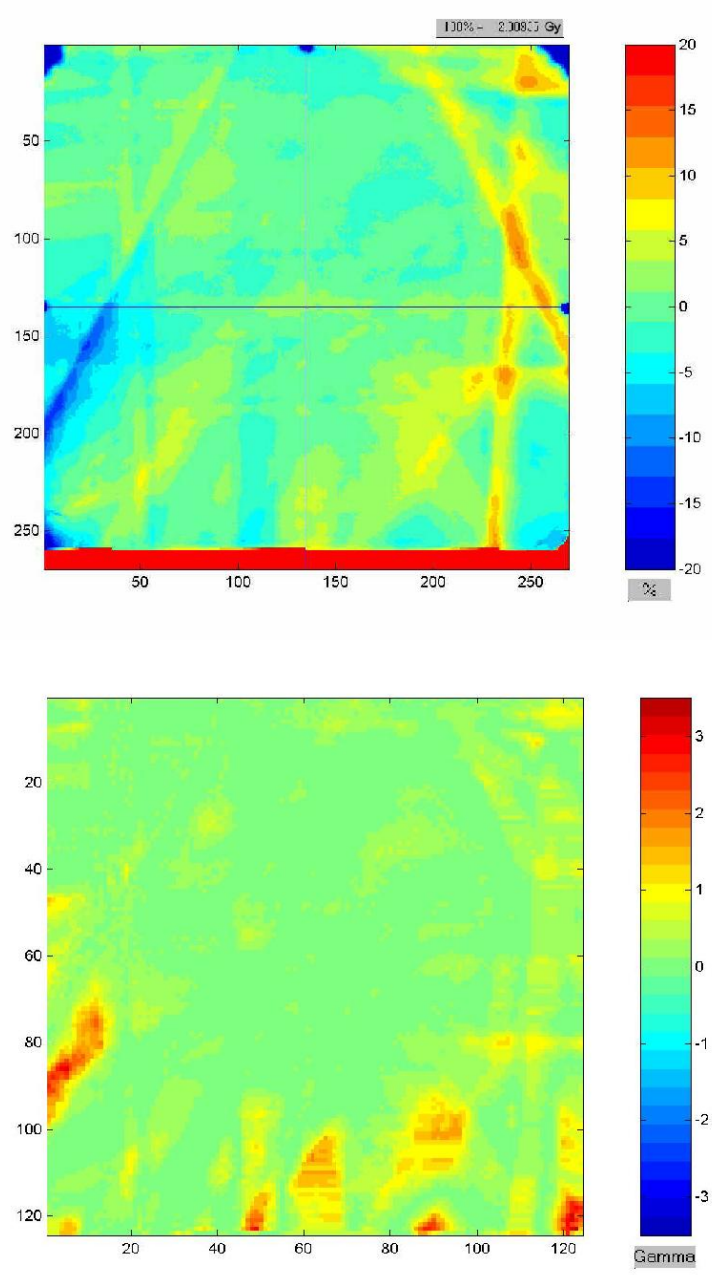
Figure $8 \mathrm{a}$ to $8 \mathrm{c} \quad$ Dose verification of the IMRT plan in the transfer phantom. a) film and calculated absolute dose distribution in one distinct slice. b) relative difference of the dose distributions. c) Gamma plot.

Abbildung 8a bis 8c Dosisverifikation eines IMRT-Plans im Transferphantom. a) Film und berechnete Absolutdosisverteilung in einer Schichte. b) relative Differenz der beiden Dosisverteilungen. c) Gammaplot.

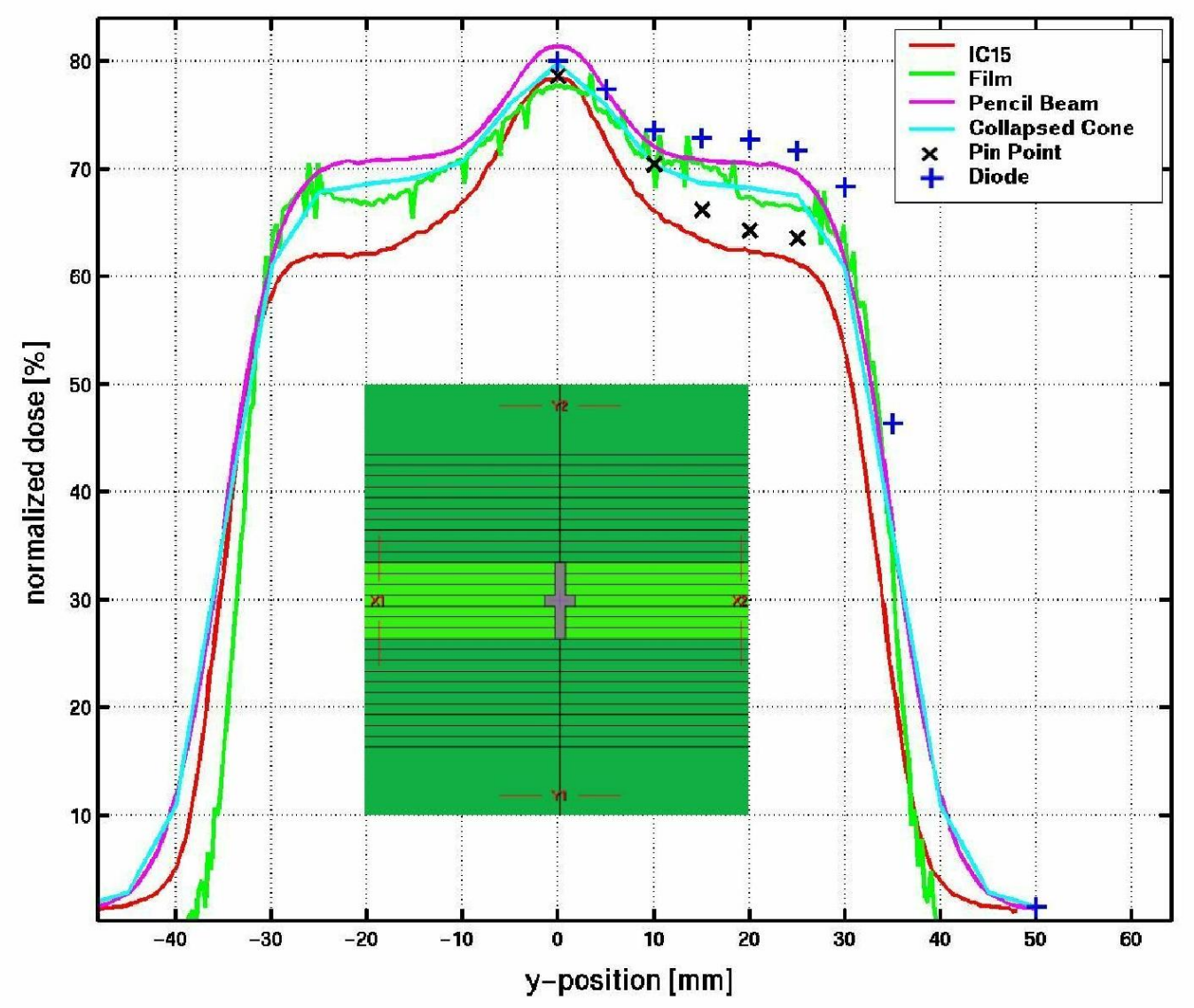

Figure 9 Dose profile for the shown small irregular field, measured by diode, IC15, pinpoint IC, IC15, and EDR2 film, normalized to $10 \times 10 \mathrm{~cm}^{2}$. Additionally shown are calculations by means of pencil beam and collapsed cone (TMS, Nucletron B.V.) algorithms.

Abbildung 9 Dosisprofile für ein kleines irirreguläres Feldsegment, gemessen mit Diode, IC15, Pin- Point IC, IC15 und EDR2 Film, normiert auf 10x10 $\mathrm{cm}^{2}$. Zusätzlich werden Berechnungen mit Pencil Beam und Collapsed Cone (TMS, Nucletron B.V.) gezeigt. 
Output in SSD $90 \mathrm{D} 10 \mathrm{~cm}$

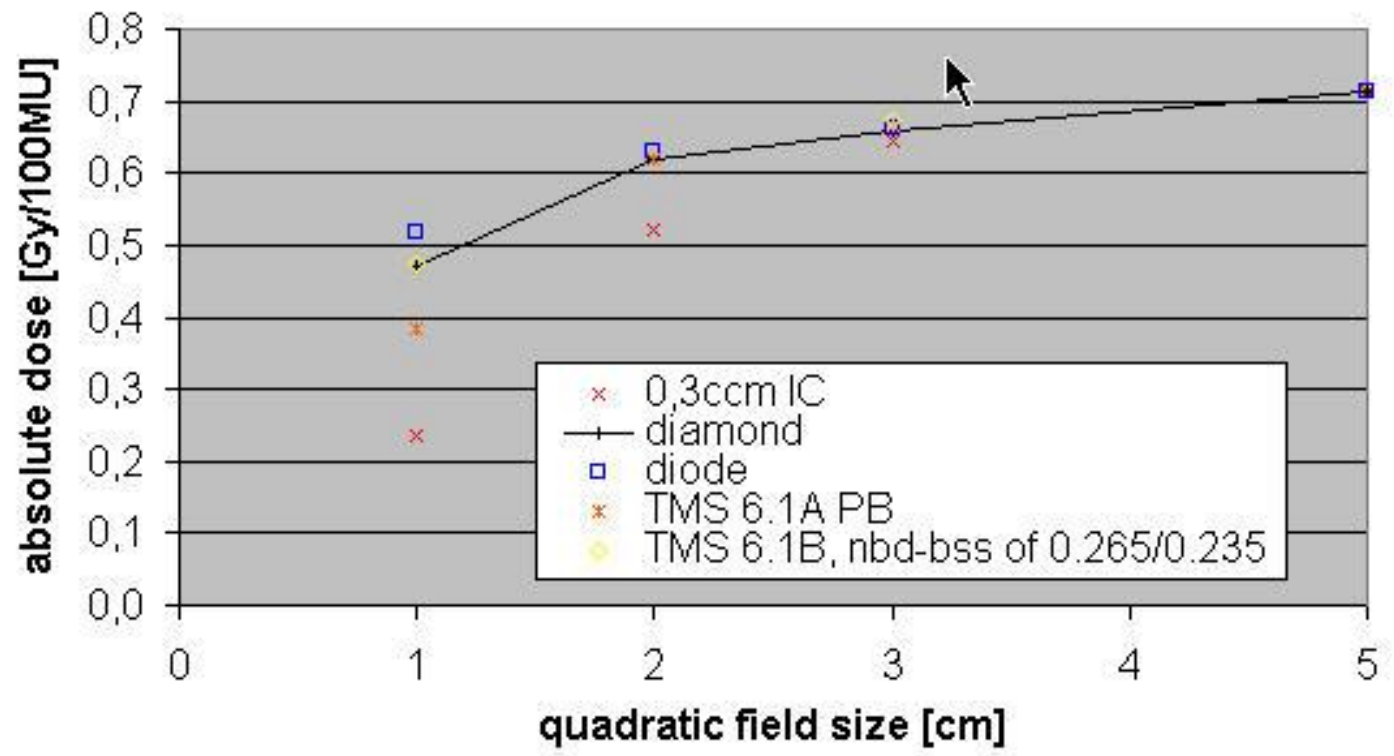

Figure 10 Absolute dose (output) as a function of field size: Comparison of $0.3 \mathrm{~cm}^{3} \mathrm{IC}$, diamond, diode and TMS 6.1A und 6.1B calculations.

Abbildung 10 Absolutdosis (Output) als Funktion der Feldgröße: Vergleich von $0.3 \mathrm{~cm}^{3} \mathrm{IC}$, Diamant und Diode mit TMS-6.1A- und -6.1B-Rechnungen.

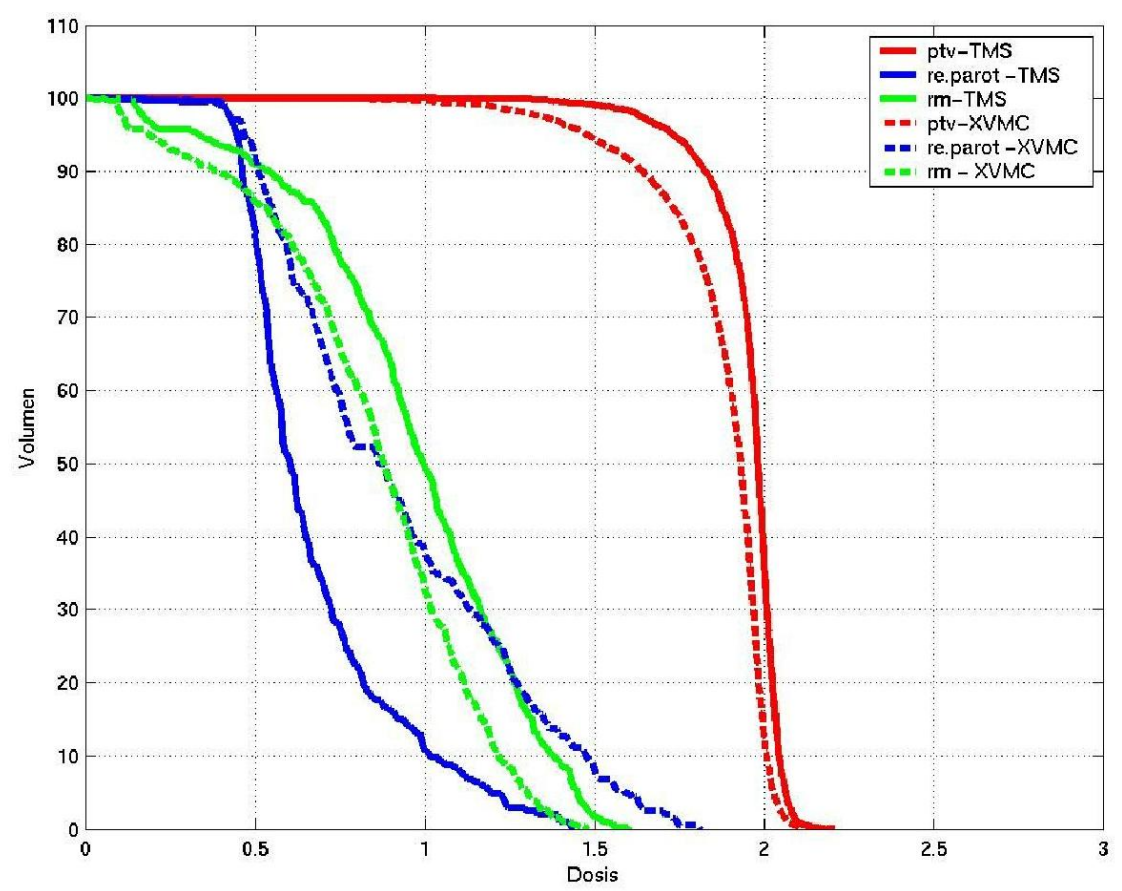

Figure 11 MC verification of the IMRT treatment plan of figure 6 by means of Figure 6 by means of XVMC/VEF by dose-volume histograms of planning target volume, spinal cord, and right parotid gland

Abbildung 11 MC Verifikation des IMRT-Plans aus Abbildung 6 mittels XVMC/VEF durch Dosis-Volumen-Histogramme des Planungszielvolumens, Rückenmarks und der rechten Parotis. 

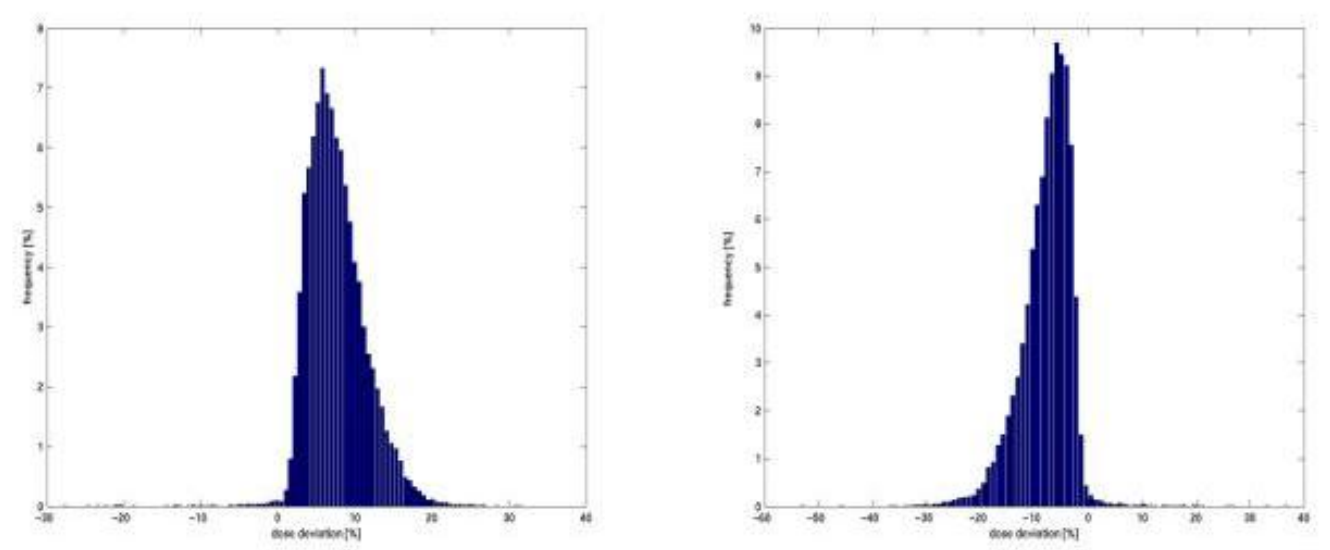

Figure 12 MC simulations of the MLC misalignment, demonstrated by means of the treatment plan of Figure 6: The histogram of [100x (dose with deviating leaf positions - dose with optimal leaf positions)/dose with optimal leaf positions] is shown. Left: all leaves of all segments opened by $2 \mathrm{~mm}$. Right: all leafs closed by $2 \mathrm{~mm}$.

Abbildung 12 MC-Simulationen zur MLC-Dejustierung am Beispiel der Dosisverteilung des Planes aus Abbildung 6: Dargestellt ist die Histogrammverteilung der Größe [100x (Dosis bei abweichenden MLC-Positionen - Dosis bei optimalen MLCPositionen)/Dosis bei optimalen MLC-Positionen)]. Links: alle Leaves aller 70 Segmente um $2 \mathrm{~mm}$ geöffnet. Rechts: alle Leaves um $2 \mathrm{~mm}$ geschlossen. 